\title{
Research on E-learning Strategies to Cultivate Middle School Students' English Autonomous Learning Ability under the Background of "Internet+"
}

\author{
Xiaoqing Rao \\ China West Normal University, Nanchong, Sichuan, China
}

\begin{abstract}
Autonomous learning is crucial to improve students' comprehensive ability. In the era of rapid development of the Internet, E-Learning has become one of the main ways for students to learn independently. This article will discuss the development strategies of middle school students' autonomous learning ability from the development of the concept of autonomous learning, the characteristics of students' learning in E-Learning, and how teachers guide middle school students to use E-Learning correctly.
\end{abstract}

Key words: Internet plus education; English autonomous learning ability; strategic research

\section{Introduction}

With the rapid development of today's society, knowledge updates more and more quickly, and the cycle is also shorter and shorter. Students have strong competitiveness and development potential depends largely on whether they have strong independent learning ability. In recent years, the country and society have paid more and more attention to the cultivation of students' autonomous learning ability. People have a deeper understanding of the theory of "autonomous learning" and more originality, since the study of "autonomous learning" was established as an important national educational science project. The study of "autonomous learning" has become a hot topic in the field of pedagogy. In the context of "Internet plus education", what kind of sparks can generate between the rational use of E-learning and the cultivation of middle school students' English autonomous learning ability ? This article will discuss the development of the concept of autonomous learning, the characteristics of E-Learning, guiding middle school students to use E-Learning correctly, and the cultivation of autonomous learning ability.

\section{Development of the Concept of Autonomous Learning}

Holec formally introduced the concept of autonomous learning into the field of language teaching in the 1980s. He first proposed "learner autonomy" and defined it as "the ability to be responsible for one's own learning" (Holec 1981). Specifically, it includes determining learning objectives and content, choosing learning methods, self-monitoring, and selfevaluating learning results, etc. Littlewood (1999) further divides autonomous learning into proactive autonomy and reactive autonomy: the former refers to learners to determine their own learning direction and learn independently, and the

Copyright (C) 2021 by author(s) and Frontier Scientific Research Publishing Inc.

This work is licensed under the Creative Commons Attribution International License (CC BY 4.0).

http://creativecommons.org/licenses/by/4.0/ 
latter refers to learners to carry out corresponding learning activities under the premise that the learning direction is established by the teacher. Another characteristic of the development of the concept of autonomous learning is to emphasize the social characteristics of autonomous learning. Autonomous learning depends not only on individuals, but also on groups. Learners can better acquire autonomous learning ability only by cooperating with others. "The ability to fully participate in social interaction critically" is the core of autonomous learning (Littlewood 1996). We realize that autonomous learning is not the same as independent learning, while mutual discussion and support is an important factor in the development of autonomous learning ability.

The ability to learn independently has become one of the key abilities to be cultivated in this era with the fast development of the Internet and information technology. The network information society has endowed autonomous learning with a new era of connotation-information literacies. This is worth keeping a close eye on the development of autonomous learning towards information literacies under the network environment.

\section{Features of E-Learning}

3.1 Teach students in accordance with their aptitude, and focus on student-centered teaching

The biggest feature of online learning is that it is student-centered and it will not be restricted by classrooms and teachers. On the Internet, students can choose the difficulty of the course that suits them according to their own learning foundation. Learners become proactive actors and explorer instead of passively accepting and instilling learning under Elearning. This process is to cultivate students' autonomous learning ability and creative critical thinking, which is conducive to more efficient absorption of new ideas and knowledge. This huge change makes teachers from traditional knowledge irrigators to the participants and organizers of teaching and activities, and teachers can better design teaching from the perspective of students.

3.2 The process of individualized interaction and socialized interaction

Students' independent learning of knowledge through the Internet is actually the organic unity of individualized interaction and socialized interaction. Individualized interaction refers to the interaction between learners and learning resources, while social interaction refers to the interaction of learners with classmates, teachers, netizens, and experts during the learning process on the Internet. The former can cultivate learners' ability to collect and analyze data independently, and build critical thinking. The latter is conducive to learners to learn to how to share and cooperate and then cultivate their ability to explore knowledge by themselves.

\section{Guide Middle School Students to Use E-Learning Correctly}

4.1 Cultivate the self-learning consciousness of middle school students

The learners' autonomous learning ability is not born naturally, but slowly cultivated. The consciousness of autonomous learning is the core and prerequisite of the ability of autonomous learning. It is well-known that consciousness will guide behavior. When learners have established the consciousness of autonomous learning, they will naturally take the initiative to explore learning. The students faced by middle school English teachers are in the semi-ignorant stage of adolescence. It is necessary for teachers to deliberately cultivate students' self-learning awareness and help students establish self-learning beliefs.

4.2 Teach students the strategies of autonomous learning

When students have the awareness of autonomous learning, teachers should help students find strategies and methods for autonomous learning that suit them. Learners mastering certain autonomous learning strategies are conducive to stimulating their learning interest and motivation. Learners' learning efficiency and behaviors and attitudes can be improved under the guidance of learning strategies. Teachers can use the model of "display, demonstration, training, 
evaluation, and expansion" to systematically introduce the connotation of autonomous learning ability and the corresponding autonomous learning strategies.

4.3 Provide opportunities for students to demonstrate the results of independent learning and then promote students' mutual exchanges and stimulate their interest

In the process of cultivating learners' autonomous learning ability, teachers should also provide learners with opportunities and platforms to display the results of independent learning, so that learners can share and learn from each other and learn from each other in addition to teachers' encouragement and enhancing learners' autonomous learning awareness. Especially in the middle school period, students are good at expressing themselves. This showing opportunity can greatly promote the enthusiasm and initiative of students at this stage. The display of self-learning results can be divided into class display and campus display. The class display is for students in the same class to learn from each other while it is the best time for the whole school to learn and observe together in the campus display. The development of these activities not only provides students with real context and opportunities to practice the target language, but also afford a large amount of independent learning experience for students to learn together.

\section{Conclusions}

In the era of rapid development of the Internet, the current knowledge of students may be subverted by the times in ten years. It is an urgent thing for teachers to cultivate students' autonomous learning ability. In the complex future development of the world, whether students can stand out, whether they can continue to develop, whether they have the ability to apply what they have learned in the era of knowledge explosion, fundamentally speaking, all depend on the autonomous learning ability. Autonomous learning ability is the need of individual development. Autonomous learning is the main learning method that an individual adopts after leaving school. Without autonomous learning ability, an individual's life-long development will be greatly restricted. As a teacher, we should pay attention to the cultivation of students' independent learning ability, promote the comprehensive improvement of students' comprehensive ability, and finally make them a competitive person.

\section{Conflicts of Interest}

The author declares no conflicts of interest regarding the publication of this paper.

\section{References}

[1] Xu J.F. (2019). Research on the Development Law and Influencing Factors of Chinese College Students' English Autonomous Learning Ability. Foreign Languages in China, (05):36-42.

[2] Xu J.F. (2020). The Composition and Cultivation of the Autonomous Learning Ability of Foreign Language Majors. Foreign Language World, (06):26-32+62.

[3] Hu X.J. (2014). A Probe into the Mediating Role of Teachers in the Autonomous Learning Model of Foreign Languages in Universities. Shaanxi Education, (04):37-39.

[4] Kyoko Baba, Ryo Nitta. (2014). Phase Transitions in Development of Writing Fluency From a Complex Dynamic Systems Perspective. Language Learning, 64 (01):1-35.

[5] Masumi Kojima, Junko Yamashita. (2014). Reliability of Lexical Richness Measures Based on Word Lists in Short Second Language Productions. System, (42):23-33.

[6] Holec H. (1981). Autonomy and Foreign Language Learning. Oxford: Pergamon Press.

[7] Littlewood W. (1999) . Defining and developing autonomy in East Asian contexts. Applied Linguistics, 20(01):7194.

[8] Littlewood W. (1996). "Autonomy": An anatomy and a framework. System, 24(04):427-435. 